\title{
New Insights into Molecular Basis Identification of Three Novel Strains of the Bacillus Subtilis Group Produce Cry Proteins Isolated from Soil Samples in Adana, Turkey
}

4

Semih Y1lmaz ${ }^{1,2}$, Abeer Babiker Idris ${ }^{3 *}$, Abdurrahman Ayvaz ${ }^{4}$, Aysun Çetin ${ }^{5}$, Funda Ülgen ${ }^{6}$, Mustafa Çetin², Berkay Saraymen7, Mohamed A. Hassan²,8,9,10

${ }^{*}$ Corresponding author: abeer.babiker89@gmail.com

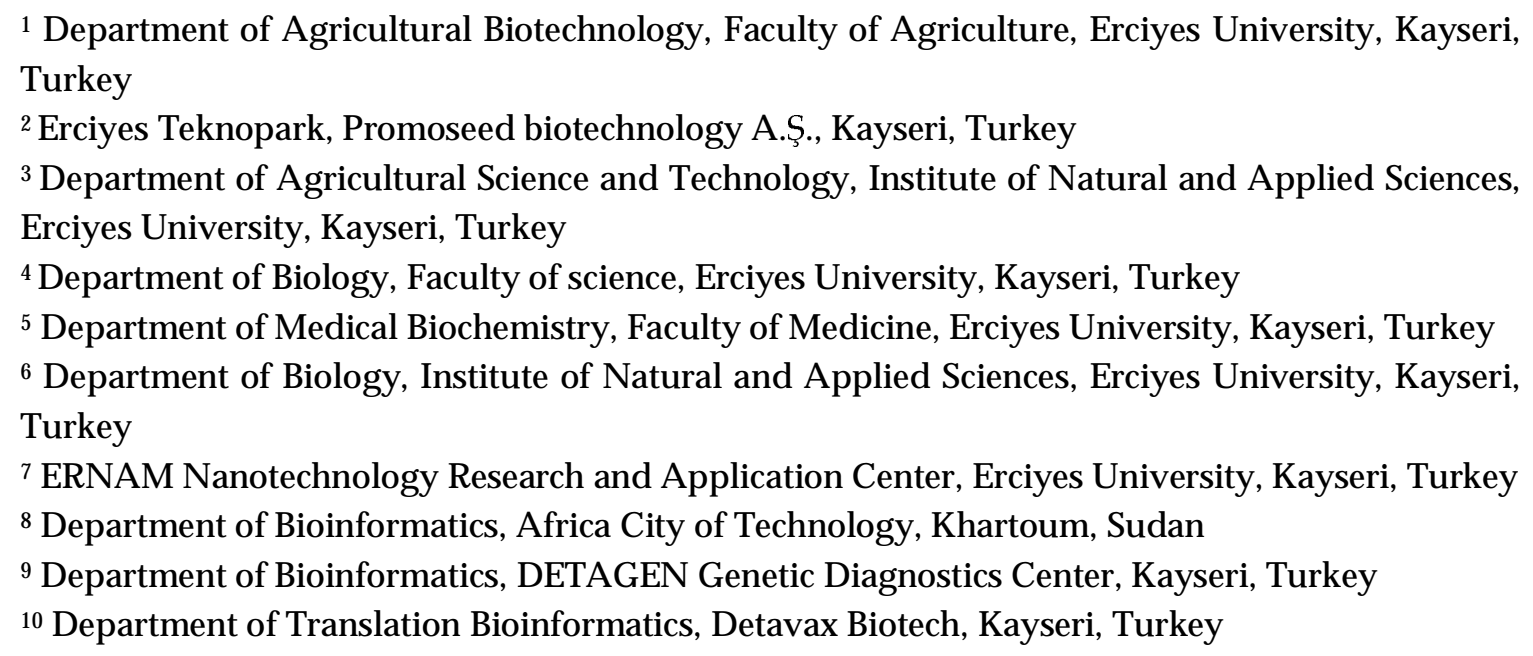




\section{Abstract}

\section{Aims}

33 This study aimed to analyze the evolutionary relationship between Bacillus species

34 isolated from agricultural soil using in-silico tools.

\section{Methods and Results}

36 Across-sectional study was conducted in Adana province, in Turkey. A total of 120

37 Bacillus species were isolated from 80 soil samples. However, the phylogenetic tree

38 diverged into two lineages; one belongs to $B$. subtilis group while the other belongs to $B$.

39 cereus group. Interestingly, three native strains (SY27.1A, SY35.3A, and SY58.5A), which

40 produce Cry proteins, shared high similarity with B. subtilis group (over 99\%) and less

41 than 95\% similarity with known B. thuringiensis and other species of B. cereus group.

42 Furthermore, 11 canonical SNPs (canSNPs) were identified in strains that belong to $B$.

43 pumilus group when compared with B. subtilis reference sequences.

\section{Conclusions}

45 Phylogenetic analysis of $16 S$ rRNA sequences was found valuable for differentiation

46 between Bacillus species isolated from soil samples. In addition, SNPs analysis provided

47 more intra-specific information in the cases of B. subtilis group.

\section{Significance and Impact of Study}

49 A detailed analysis was provided for the SNPs present in a conserved region of 165

50 rRNA gene of Bacillus species. Also, we proposed three novel Bacillus strains that

51 produce Cry proteins and belong to B. subtilis group.

53 Keywords: Bacillus species, 16S rRNA gene, evolutionary tree, canonical SNPs, Turkey. 


\section{Introduction}

57 Bacillus is agriculturally important insecticidal bacterial genus that naturally

58 inhabit the phyllosphere and rhizosphere (1). It consists of a heterogeneous

59 group of Gram-positive, endospore-forming, aerobic or facultative anaerobic

60 organisms (2). Most members of the genus Bacillus have the ability to produce

61 antibiotics, enzymes, vitamins, proteins, or secondary metabolites that are

62 capable to induce defense mechanisms and promote growth in animals and

63 plants $(3,4)$. Benefiting from their metabolic diversity and spore dispersal,

64 Bacillus is ubiquitous in various natural environments especially terrestrial

65 environments (5). At the time of writing, the genus Bacillus consisted of more

66 than 408 species with validly published names (LPSN,

67 http:/ / www.bacterio.net), only 54 species of them were reported before 2000 (6).

68 Analysis of $16 S$ rRNA gene, the "ultimate molecular chronometer", has been

69 extensively applied for bacterial phylogeny and taxonomy which resulted

70 eventually in the establishment of large public-domain databases (7-11). The $16 S$

$71 \quad r R N A$ gene characterizes by several properties which include being present in all

72 bacteria, thus it is a universal target for bacterial identification and

73 characterization $(12,13)$. In addition, the function of $16 S r R N A$ has not changed

74 over a long period, i.e. random sequence changes are more likely to reflect the

75 microbial evolutionary change (phylogeny) (11), and any introduction of selected 
76 changes in one domain does not greatly affect sequences in other domains (13,

77 14). Based on phylogenetic analysis of the $16 S$ rRNA gene, the species and strains

78 in Bacillus are divided into five groups: B. cereus, B. megaterium, B. subtilis, B.

79 circulans and B. brevis groups (15).

80 The B. subtilis group is a tight assemblage of closely related species which

81 includes B. subtilis, B. amyloliquefaciens, B. atrophaeus, B. axarquiensis, B.

82 malacitensis, B. mojavensis, B. sonorensis, B. tequilensis, B. vallismortis and $B$.

83 velezensis (16). These species share high genetic homogeneity (over 99.5\%) and

84 cannot differentiate on the basis of phenotypic or biochemical characteristics (15,

85 16). In addition, B. pumilus and their relatives belong to the subtilis group (17).

86 The B. pumilus group, which is a large group of Bacillus, composed of B. pumilus,

87 B. altitudinis, B. safensis, B. zhangzhouensis, B. xiamenensis, and B. australimaris (5).

88 The bacteria of $B$. cereus group share high genetic homogeneity despite their

89 phenotypic diversity, with over 97\% $16 S$ rRNA sequence similarity among $B$.

90 cereus, B. anthracis, B. thuringiensis, B. weihenstephanensis, B. mycoides, B.

91 pseudomycoides, B. cytotoxicus, B. gaemokensis and B. manliponensis (18). Moreover,

92 this group is of interest to researchers, especially B. thuringiensis, because of their

93 significance in agriculture, industry and medicine (19). B. thuringiensis acts as a

94 biological control agent against different phytopathogenic organisms due to their

95 ability to produce insecticidal proteins (Cry, Vip, Sip, Bin, etc), fungicidal

96 metabolites (iturin, fengycin, surfactin, zwittermycin, etc) (20, 21). Also, $B$. 
97 thuringiensis can promote plant growth by producing ACC deaminase, 98 phosphatases, siderophore, etc $(22,23)$. However, the isolation and 99 characterization of native Bacillus species or strains, especially from agricultural 100 soil, should receive a good attention because of their wide potential biological 101 products with immense applications. In addition, there are several studies on the 102 isolation and characterization of native Bacillus strains of soil in order to identify 103 novel toxins with high level of toxicity and effective against agricultural pests 104 (24-26). Finding of novel toxins produce from Bacillus species, especially $B$. 105 thuringiensis, will delay the resistance within the pests due to the use of existing 106 Bacillus toxins. Therefore, in this study, we aimed to characterize and establish a 107 phylogenetic relationship between Bacillus species isolated from agricultural soil 108 in Adana, one of the most fertile agricultural area in Turkey, by reconstructing $10916 S$ rRNA phylogenetic trees using in silico tools. Also, a detailed analysis was 110 provided, for the SNPs present in a conserved region of $16 S$ rRNA gene of $B$.

111 cereus group, B. Subtilis group and B. pumilus group. The results of canonical 112 SNPs (canSNPs) are of great significance for the design of primers or probes 113 specific to a strain, species, or group of species. 


\section{2. Materials and Methods}

\section{$118 \quad 2.1$ Study Settings and Sample collection}

119 A cross-sectional study was conducted in Adana province, which is located in

120 the southern region of Turkey. Adana province is divided into 13 districts with

121 different texture. For the isolation of bacterial strains, 80 different soil samples

122 were collected throughout Adana province from different altitudes ranging from

1230 to 1582 meters. Soil samples have been taken in a depth of 2-10 centimeters and

124 stored in sterile tubes at $4^{\circ} \mathrm{C}$ for the studies.

\section{$125 \quad 2.2$ Bacterial Isolation and Identification}

126 Isolation processes has been performed according to the method of Travers et al.

127 (27). One gram of soil sample was inoculated in LB medium ( $\mathrm{pH} 6.8 \pm 2$ ) including

$1280.25 \mathrm{M}$ sodium acetate in a shaking incubator at $200 \mathrm{rpm}$ at $30^{\circ} \mathrm{C}$ for 4 hours. After

129 the incubation step, $1.5 \mathrm{ml}$ of liquid samples have been transferred to a sterile

130 Eppendorf tube and exposed to $80^{\circ} \mathrm{C}$ for 10 minutes to kill the vegetative

131 bacterial forms. A 20-50 ul of samples were spread on LB agar plates and

132 incubated overnight at $30^{\circ} \mathrm{C}$. The colonies with morphological differences have

133 been spread on agar plates and pure colonies were obtained. Pure colonies were

134 incubated in $5 \mathrm{ml} \mathrm{LB}$ broth $(\mathrm{pH} 6.8 \pm 2)$ in $50 \mathrm{ml}$ tubes at $200 \mathrm{rpm}$ and $30^{\circ} \mathrm{C}$ 135 overnight. 
136 Then the colonies were homogenized in $400 \mu$ of sterile $\mathrm{dH}_{2} \mathrm{O}$ in microfuge tubes

137 and 10 ul were added onto sterilized Watman no:1 paper disc with $0.4 \mathrm{~mm}$

138 diameter. The discs were then placed into Potato Dextrose agar (PDA) plates and

139 incubated overnight at $30^{\circ} \mathrm{C}$. Morphologically pale-yellow, grayish white, pale-

140 pink, ciliated, or wrinkled ends, round-shaped outlines were selected for Gram

141 stain (28). Gram- positive colonies were further investigated for spore production

142 using Malachite green (5g / $100 \mathrm{ml})$ staining as previously described (29).

2.3 Characterization of para-sporal inclusions

144 To characterize para-sporal inclusions, the bacteria were incubated in $150 \mathrm{ml}$ of

$1453 \mathrm{~T}$ medium (2 g triptose, $3 \mathrm{~g}$ triptone, $1.5 \mathrm{~g}$ yeast extract, $6 \mathrm{~g} \mathrm{NaH} \mathrm{PO}_{4}, 0.005 \mathrm{~g}$

$146 \mathrm{MnCl}_{2}$ and $\left.7.1 \mathrm{~g} \mathrm{Na}_{2} \mathrm{HPO}_{4}\right)$ at $200 \mathrm{rpm}$ and $30^{\circ} \mathrm{C}$ for 7 days to induce sporulation

147 (27). Then, to harvest spore-crystal mixtures, the suspensions were centrifuged at

$14815000 \times \mathrm{g}$ and $4^{\circ} \mathrm{C}$ for $10 \mathrm{~min}$. After that, the mixtures were suspended in $\mathrm{dH}_{2} \mathrm{O}$

149 on microscope slides and fixed. Finally, the slides were sputter coated with 10

$150 \mathrm{~nm} \mathrm{Au} / \mathrm{Pd}$ using a SC7620 Mini-sputter coater and viewed using a LEO440

151 scanning electron microscope (SEM) at $20 \mathrm{kV}$ beam current $(30,31)$ in this study

152 reference standard B. thuringiensis strains such as Bt. kurstaki HD1, Bt. kurstaki

153 HD73, Bt. aizawai (Universidad Nacional Autonoma de Mexico Biyotechnology

154 Institute), Bt. morrisoni, Bt. israelensis (Pasteur Institute, Paris, France) and, Bt.

155 tenebrionis (Plant Genetic Systems, J. Plateaustroat 22, 900 Gent, Belgium) were

156 used for comparison with the native local isolates. 


\subsection{Genetics analysis}

\subsubsection{Determination of the insecticidal crystal genes (cry) carrying isolates}

159 Extraction of DNA was performed according to a previously described method

$160(32,33)$. Briefly, the bacteria were grown in LB medium for overnight, and then a 161 loopful of cells was placed into $400 \mu \mathrm{l}$ sterile $\mathrm{dH}_{2} \mathrm{O}$. Then the mixture was boiled 162 for 10 min to lyse the cells. The resulting cell lysate was centrifuged for $10 \mathrm{sec}$ at $16310.000 \mathrm{rpm}$ and the supernatant was used as DNA templates for PCR reactions. 164 The extracted DNA from the isolates was used to determine the cry genes 165 carrying strains. In our previous work, we have characterized the isolates using 166 cry genes cry1Ab/Ac, cry1Aa/Ad, cry2, cry5, and cry9C, cry1C, cry1Ad, cry1Ac, 167 cry $1 D, \operatorname{cry} 1 B$, cry3-7-8, cry $4 A$, cry $9 A$, and cry $11 A / B(30,31)$.

\subsection{Amplification and sequencing of $16 S r R N A$ gene}

169 The extracted DNA was used to amplify the $16 S r R N A$ gene of Bacillus species

170 using universal primers with the following sequences: F: 5'-AAA CTY AAA KGA

171 ATT GAC GG-3' and R: 5'-ACG GGC GGT GTG TRC-3'. The thermal procedures 172 were performed with ABI veriti Thermocycler and the PCR mixtures contained $1732.3 \mathrm{mM} \mathrm{MgCl2}$, 1x Taq buffer, $0.2 \mathrm{mM}$ dNTP mix, 0.3 pmol for each primer, $0.5 \mathrm{U}$ 174 Taq DNA polymerase, and 30-100 ng template DNA. The PCR conditions were 175 an initial denaturation $94^{\circ} \mathrm{C} 5 \mathrm{~min}$, then 40 cycles of denaturation at $94^{\circ} \mathrm{C}$ for $1761 \mathrm{~min}$, primer annealing at $48^{\circ} \mathrm{C}$ for $1 \mathrm{~min}$, extension at $72^{\circ} \mathrm{C}$ for $2 \mathrm{~min}$, and then 
177 additional extension step $72^{\circ} \mathrm{C}$ for $10 \mathrm{~min}$. The size of expected PCR products was $178850 \mathrm{bp}$.

179 For sequencing, the DNA fragments were extracted from the gel using a 180 EasyPure ${ }^{\circledR}$ Quick Gel Extraction Kit (EG101-01) according to the manufacturer's 181 instruction. Then the PCR products of 21 samples, which have the clearest bands, 182 were sent for commercial DNA purification and Sanger dideoxy sequencing by 183 DETAGEN Genetic Diagnostics Center Inc., Turkey.

\subsection{Bioinformatics analysis}

186 The two chromatograms for each strain (forward and reverse) were visualized, 187 checked the quality, and analyzed using the Finch TV program version 1.4 .0 (34).

188 The bacterial strains were identified by searching for their homology among 189 published reference sequences using the nucleotide Basic Local Alignment 190 Search Tool (BLASTn; https://blast.ncbi.nlm.nih.gov/) (35). To determine the 191 SNPs, multiple sequences alignment (MSA) was accomplished with reference 192 sequences of Bacillus species using BioEdit software (36) and MEGA version 7.0 193 software (37). This MSA facilitated the use of polymorphisms to detect potential 194 relationships between the Bacillus strains and species. In addition, the detected 195 SNPs were carefully reviewed by eye using the Finch TV software; and 196 polymorphisms present in both the forward and reverse strands were 197 considered. 


\section{$198 \quad$ 2.5. 2 Molecular phylogenetic analysis}

199 For building the phylogenetic tree, the studied sequences and their highly similar

200 references sequences that retrieved from the NCBI GenBank were subjected to

201 Gblocks software to eliminate poorly aligned positions and divergent regions of

202 aligned sequences, so the alignment becomes more suitable for phylogenetic

203 analysis (38). The molecular evolutionary analyses were conducted with MEGA

2047.0 software (37) using the maximum likelihood (ML) method and neighbour-

205 joining $(\mathrm{NJ})$ method $(39,40)$. The Kimura 2-parameter $(\mathrm{K} 2+\mathrm{G})$ model from the

206 substitution (ML) model was used with 1000 bootstrap replicates to construct

207 distance-based trees $(41,42)$.

208

211 3. Results

\section{$212 \quad 3.1$ Bacterial isolation and characterization}

213 A total of 120 Bacillus species were isolated from 80 soil samples. Eighty-eight of Bacillus

214 isolates harbored cry genes. The cry genes were determined and characterized using

215 conventional PCR. Also, spore-crystals of some of the samples were examined under the

216 SEM. The results in details were presented in our previous works $(30,31)$. In the current

217 study, 16S rRNA of 21 Bacillus species were amplified and sequenced to construct a 
218 phylogenetic tree. Among them, six strains were characterized by producing Cry

219 proteins. The morphology of spore-crystals and cry genes profiles of the native Bacillus

220 isolates are illustrated in Table 1. The nucleotide sequences of the $16 S$ rRNA were

221 deposited in the GenBank database under the following accession numbers: from

222 OK428682 to OK428687 and from OK384678 to OK384692.

223 Table 1. The morphology of spore-crystals and cry gene profiles of the native Bacillus

224 isolates

\begin{tabular}{lll}
\hline Isolates & Cry forms & cry genes \\
\hline SY49.1 & bp & cry1Aa/Ad, cry1B, cry1C, cry5, cry9A, cry9C \\
SY27.1A & bp, cs, ss, pe & $c r y 1 A d, c r y 1 A c, c r y 1 A b / A c, c r y 1 B, c r y 2, c r y 9 C$ \\
SY35.3A & ss & $c r y 3-7-8$ \\
SY58.5A & bp, cs & $c r y 1 A c, c r y 1 A b / A c, c r y 2$
\end{tabular}

SY10.1A bp cry1Ac

SY25. 1A bp cry1C, cry1Ab/Ac, cry1Aa/Ad

225 bp: bipyramidal; ss: smooth spherical; pe: spherical crystal with pointy edges; cs, cuboidal

$226 \quad 3.2$ Sequencing analysis of $16 S$ rRNA gene

227 Twenty-one isolates of Bacillus species were subjected to PCR amplification and

228 nucleotide sequencing using universal $16 S r R N A$ primers but specific for a conserved

229 region of the gene which was located between $629 \mathrm{bp}$ and $1552 \mathrm{bp}$. The sequences of the

230 studied strains were aligned with reference sequences of Bacillus species retrieved from

231 NCBI databases. The information about the retrieved strains is given in supplementary

232 Table S1. 
233 As presented in Figure 1, 11 strains revealed high similarity with the B. cereus group

234 (over 99\%), see Figure 1. Among them, seven strains, which were found to be

235 homogenous, revealed two nucleotide variations (A1015C and A1146T). Numbers are

236 given in all sequences in accordance with numbering in the $B$. thuringiensis genome

237 (NZ_CM000747). Six of these strains (SY49.1, SY10.1A, and SY25.1A) were characterized

238 by the production of Cry proteins. While six and four of the studied strains exhibited

239 high similarities to B. subtilis group and B. pumilus group, respectively (Figure 3).

240 Interestingly, three of native strains (SY27.1A, SY35.3A, SY58.5A), which produce Cry

241 proteins, shared high similarity with B. subtilis group (over 99\%) and less than 95\%

242 similarity with known B. thuringiensis and other species of B. cereus group, see Figure 2.

$243 \quad 3.3$ Molecular phylogenetic analysis

244 The evolutionary analysis of 21 native Turkish Bacillus strains, based on $16 S$ rRNA gene,

245 was conducted with reference sequences of Bacillus species retrieved from NCBI

246 GenBank databases. Neighbor-joining (NJ), maximum-likelihood (ML) analyses were

247 performed with MEGA 7 (37). The topology of the ML and NJ trees was similar, and the

248 bootstrap supports of the NJ tree were approximately higher than those of ML. The

249 phylogenetic tree diverged into two lineages; one belongs to B. subtilis group while the

250 other belongs to B. cereus group (Figure 4).

251 The lineage of B. subtilis group branched into two major clades (I and II). In clade I, six

252 strains (SY27.1A, SY35.3A, SY58.5A, SY80, SY81 and SY85) were clustered with $B$.

253 subtilis, B. amyloliquefaciens, B. velezensis and B. mojavensis. However, SY27.1A, SY35.3A

254 and SY85 strains were closely related to B. velezensis strain CBMB205 and they shared

255 nucleotide variations at TA1461-1462AT. While in clade II, four strains (SY61.6, SY82, 
256 SY83 and SY84) were grouped with B. pumilus group which comprises B. pumilus, B.

257 safensis, and B. altitudinis. In addition, all strains in clade II shared 11 nucleotide

258 variations with B. pumilus group (T1017C, A1030G, G1032T, C1034T, G1045A, A1265T,

259 A1270G, G1276A, A1282T, T1432C and A1485G), see Figure 3a. Four mutations (C971G,

260 C1316T, C1330T and A1543C) in strain A made it a separate minor clade. Interestingly,

261 three native strains (SY27.1A, SY35.3A and SY58.5A) that characterized by producing

262 Cry proteins, which is often considered as a feature of B. thuringiensis, were clustered

263 with B. subtilis group (Figure 2). The lineage of B. cereus group involved 11 strains. Three

264 of them (SY49.1, SY10.1A, and SY25.1A) were characterized by producing Cry proteins.

265 Moreover, seven strains shared a common ancestor and were characterized by two

266 nucleotide variations (A1015C and A1146T). However, strain SY25.1A and $B$.

267 nitratireducens strain MCCC $1 A 00732$ were sisters with a bootstrap value of $63 \%$, see

268 Figure 4 for more illustration.

272 In this study, we observed three novel Gram- positive bacilli (SY27.1A, SY35.3A, and

$273 S Y 58.5 A$ ) which produce Cry proteins but, based on the analysis of $16 S$ rRNA gene, they

274 are unlikely to belong to the known B. thuringiensis or other species of Bacillus cereus

275 group. Although the defining feature of the $B$. thuringiensis species is the ability to

276 express Cry proteins (20), the analysis of $16 S r R N A$ gene sequences of these strains

277 showed that they were sharing over $97 \%$ similarity with B. subtilis group and less than 
$27895 \%$ similarity with the known B. thuringiensis and other species of B. cereus group.

279 However, in prokaryotes taxonomy, $16 S$ rRNA gene sequence identity of $97 \%$ is

280 generally used as a threshold value for species definition, therefore, strains with less

281 than $97.5 \%$ identity are unlikely to be related at the species level $(43,44)$. This finding is

282 partially in agreement with a previous study that systematically searched for Cry

283 proteins expressed by Bacillus species, other than B. thuringiensis, genomes using

284 conserved sequences from the C-terminal half of reported Cry proteins in hidden

285 Markov Model (HMM) profiles (45). Interestingly, there were 174 Cry protein sequences

286 were observed, as expected most of them were in B. thuringiensis genomes, but 42 were

287 found in other species. In addition, several studies reported the presence of Cry proteins

288 in other Bacilli, such as P. popilliae, C. bifermentans, L. sphaericus and P. lentimorbus (46-49).

289 Nevertheless, the great diversity of Cry proteins may indicate that this family of proteins

290 may not be restricted only to the B. thuringiensis species (20), and their dispersion and

291 role in nature are could be much wider. Therefore, further studies, either based on an in-

292 silico procedure or the use of a large data collection of different species of bacilli, are

293 recommended to search for new Cry proteins with higher toxicity or different mode of

294 action, which may render alternatives in case of resistance development. However, the

295 development of resistance to insecticidal B. thuringiensis proteins has been documented

296 which raise concerns about the adequacy of current resistance management strategies

297 (54). Hence, continuous searching for novel Bacillus species with novel insecticidal genes

298 to delay the development of insect resistance is of the utmost importance. In this

299 connection, to isolated novel Bacillus strains, we collected soil samples throughout

300 Adana province. This region is rich in biodiversity due to its unique climate and

301 geographical location that is situated on the fertile and watery delta of Seyhan and 
302 Ceyhan rivers, furthermore in this study, the genetic identity based on $16 S$ rRNA 303 sequences indicated that three native strains of Bacillus (SY27.1A, SY35.3A, and 304 SY58.5A), which produce Cry proteins were close relatives of the B. subtilis group and 305 appeared to be discrete from the B. cereus group. However, according to the low 306 discrimination of the $16 S$ rRNA gene between Bacillus species, it cannot be assigned 307 accurately as a certain species (55), therefore, complete genome sequencing of these 308 bacterial strains is recommended. While, the other ten Bacillus strains, which clustered 309 with B. cereus group, showed diversity into two minor clades. Seven of them shared a 310 common ancestor and were characterized by two nucleotide variations (A1015C and 311 A1146T). This finding is in agreement with other studies conducted in different 312 countries which showed diversity in B. cereus / B. thuringiesis strains isolated from soil 313 and other natural sources $(24,26,56-58)$.

314 Furthermore, in the phylogenetic tree of the native strains with global reference 315 sequences of Bacillus species, the lineage of B. subtilis group were branched into two 316 major clades. Clade I contained B. amyloliquefaciens, B. velezensis, B. mojavensis along with 317 B. subtilis which is not entirely unexpected since these species share a remarkably high 318 level of $16 S$ rRNA gene sequence similarity to B. subtilis (often $99 \%$ or greater) (16). 319 While in clade II, the members of B. pumilus group (B. pumilus, B. altitudinis, and B. 320 safensis) were clustered together along with four strains (SY61.6A, SY82, SY83, and 321 SY84). They shared 11 nucleotide variations when their $16 S$ rRNA sequences compared 322 with B. subtilis reference sequences, see Figure 3a. In 1973, Gordon et al. speculated that 323 B. pumilus might one day be considered a variety of B. subtilis rather than a separate 324 species once more data were collected (59). Intriguingly, our findings are in agreement 
325 with Rooney et al. results which clearly indicated that the B. pumilus forms a clade

326 distinct from B. subtilis (16).

327 However, single nucleotide polymorphism (SNP) analysis has emerged as one of the

328 most useful molecular methods proposed for microbial characterization and improving

329 discrimination among closely related species (60-62). Accordingly, we used universal

330 primers of $16 S r R N A$ in order to produce a mixture of amplicons from all $r R N A$ operons

331 in the genome. Although there are small differences exhibit by the multiple $r R N A$ gene

332 copies in each genome, these differences do not invalidate bacterial identification and

333 characterization based on $16 S r R N A$ sequences $(63,64)$. Moreover, these differences

334 between $r R N A$ operons appear in multiple peaks (two or more) at a single nucleotide

335 position in the case of SNPs. But in the case of InDels variations, the sequence loses

336 synchronicity and makes an abrupt change, from clean to dirty, following an InDel

337 mutation (65), for more illustration see Figure3b. In the present study, we provided a

338 detailed analysis of the SNPs present in the 16S rRNA gene of Bacillus species isolated

339 from soil samples. Of great significance, dual peaks (A and T) at position 1146, which

340 were previously reported to be specific to $B$. anthracis (66), were detected in three $B$.

341 thuringiensis / B. cereus strains (PSY6.1A, PSY6.2A and SY10.1A). But in all other strains, a

342 single peak (either A or T) was detected. This finding is in accordance with a study

343 conducted by Hakovirta et al. which found five B. cereus strains and three B. thuringiensis

344 strains also had A and T peaks (65). Hence, the SNP at nucleotide position 1146 is not

345 necessarily reliable for identifying B. anthracis. While, in this study, all B. thuringiensis

346 had only G at position 1139 which is another SNP proposed by Hakovirta et al. to be

347 unique to B. anthracis (65), and it appears to be more reliable for identifying B. anthracis. 
348 Regarding the B. subtilis group, we identified 11 canonical SNPs (canSNPs) in strains

349 that belong to B. pumilus groups (clade II) when compared with B. subtilis reference

350 sequences. Canonical SNPs (canSNPs) are useful and diagnostic SNPs that used for

351 identifying long branches or key phylogenetic positions (67). In addition, G1268A and

352 C1294T SNPs were specific to B. safensis and B. altitude, respectively. Also, strain SY83

353 characterized by four nucleotide variations SNPs (C971G, C1316T, C1330T and A1543C).

354 These findings are partially in agreement with a study conducted by Moorhead et al. in

355 which strains of Listeria monocytogenes were partitioned into three previously described

356 clonal lineages using a phylogenetic approach to detect a small number of SNPs in the

$357 \operatorname{sig} B$ gene (68). However, a number of researchers have found that a small number of

358 SNPs can be used to effectively identify genetic groups $(61,67,69)$. Also, Keim et. al.

359 proposed canSNPs to define the B. anthracis lineage that contains the Ames strain

360 (67).The limitations of the present study include the relatively small sample size and the

361 phylogenetic tree was built based on the $16 S$ rRNA gene only. Hence, further studies

362 with large sample size and molecular techniques, such as multilocus sequence analysis

363 (MLST) and whole genome sequencing (WGS), that are used to differentiate the closely

364 related microbial species like Bacillus species are recommended. However, in this work,

365 the SNPs analysis provided more intra-specific information than phylogenetic analysis

366 in the cases of B. subtilis group. Eleven canSNPs were identified in strains that belong to

367 B. pumilus groups when compared with B. subtilis reference sequences. In addition, these

368 canSNPs in the conserved region of $16 S r R N A$ gene may provide important information

369 for the design of primers and probes for Real-Time PCR, multiplex-PCR and microarray

370 systems which is widely used for detection and typing purposes. 
371 In conclusion, the phylogenetic tree diverged into two lineages; one belongs to $B$.

372 subtilis group while the other belongs to B. cereus group. Interestingly, three of

373 native strains (SY27.1A, SY35.3A, and SY58.5A), which produce Cry proteins,

374 shared high similarity with B. subtilis group (over 99\%). An 11 canSNPs were

375 identified in strains that belong to B. pumilus groups when compared with $B$.

376 subtilis reference sequences. These canSNPs in the conserved region of $16 S$ rRNA

377 gene may provide important information for the design of primers and probes

378 which is widely used for detection and typing purposes.

379 Supplementary file

380 Table S1. Information of the reference sequences of Bacillus species that were 381 retrieved from NCBI databases.

382 Acknowledgment

383 We gratefully acknowledge the Genome and stem cell (GenKök) research center 384 for their cooperation and supporting the study experiments.

\section{Authors' contributions}

387 Semih Yılmaz: Conceptualization, funding acquisition, methodology, writing -

388 review \& editing, and supervision; Abeer Babiker Idris: conceptualization, 389 methodology, investigation, software, data curation and formal analysis, writing 
390 - original draft; and writing - review \& editing; Abdurrahman Ayvaz: funding

391 acquisition, methodology and supervision; Aysun Çetin: methodology; Funda

392 Ülgen: methodology and writing - original draft; Mustafa Çetin: funding

393 acquisition, and supervision; Berkay Saraymen: methodology and data curation

394 and formal analysis; Mohamed A. Hassan: conceptualization, methodology,

395 writing - review \& editing, and supervision.

396 Availability of data

397 All data generated or analyzed during this study are included in the manuscript.

398 Competing of interests

399 The authors have no competing of interests to declare.

$400 \quad$ Ethical Approval

401 This study was approved by Erciyes University, Faculty of Agriculture,

402 Department of Agricultural Biotechnology.

\section{$403 \quad$ Funding}

404 This work was supported by Erciyes University Scientific Project Unit under the

405 codes of FBD11-3634; and Ministry of Industrial Science and Technology, Turkey

406 (TGSD-0802).

407 Consent of participants

408 Not applicable 


\section{References}

416 1. Huang T-P, Tzeng DD-S, Wong ACL, Chen C-H, Lu K-M, Lee Y-H, et al.

417 DNA polymorphisms and biocontrol of Bacillus antagonistic to citrus bacterial

418 canker with indication of the interference of phyllosphere biofilms. PLoS One.

419 2012;7(7):e42124-e.

420 2. Liu Y, Lai Q, Dong C, Sun F, Wang L, Li G, et al. Phylogenetic diversity of

421 the Bacillus pumilus group and the marine ecotype revealed by multilocus

422 sequence analysis. PLoS One. 2013;8(11):e80097-e.

423 3. Radhakrishnan R, Hashem A, Abd Allah EF. Bacillus: A Biological Tool

424 for Crop Improvement through Bio-Molecular Changes in Adverse

425 Environments. Front Physiol. 2017;8:667-. 
426 4. Garbeva P, van Veen JA, van Elsas JD. Predominant Bacillus spp. in

427 Agricultural Soil under Different Management Regimes Detected via PCR-

428 DGGE. Microbial Ecology. 2003;45(3):302-16.

429 5. Fu X, Gong L, Liu Y, Lai Q, Li G, Shao Z. Bacillus pumilus Group

430 Comparative Genomics: Toward Pangenome Features, Diversity, and Marine

431 Environmental Adaptation. Frontiers in microbiology. 2021;12(1084).

432 6. Parte AC, Sardà Carbasse J, Meier-Kolthoff JP, Reimer LC, Göker M. List

433 of Prokaryotic names with Standing in Nomenclature (LPSN) moves to the

434 DSMZ. International journal of systematic and evolutionary microbiology.

$435 \quad 2020 ; 70(11): 5607-12$.

436 7. Woese CR, Kandler O, Wheelis ML. Towards a natural system of

437 organisms: proposal for the domains Archaea, Bacteria, and Eucarya.

438 Proceedings of the National Academy of Sciences of the United States of

439 America. 1990;87(12):4576-9.

440 8. Van de Peer Y, Jansen J, De Rijk P, De Wachter R. Database on the 441 structure of small ribosomal subunit RNA. Nucleic Acids Research. $442 \quad 1997 ; 25(1): 111-6$.

443 9. Maidak BL, Olsen GJ, Larsen N, Overbeek R, McCaughey MJ, Woese CR.

444 The Ribosomal Database Project (RDP). Nucleic Acids Research. 1996;24(1):82-5.

445 10. Drancourt M, Bollet C, Carlioz A, Martelin R, Gayral JP, Raoult D. 16S 446 ribosomal DNA sequence analysis of a large collection of environmental and 
447 clinical unidentifiable bacterial isolates. Journal of clinical microbiology.

$448 \quad 2000 ; 38(10): 3623-30$.

449 11. Woese CR. Bacterial evolution. Microbiol Rev. 1987;51(2):221-71.

450 12. Janda JM, Abbott SL. 16S rRNA gene sequencing for bacterial

451 identification in the diagnostic laboratory: pluses, perils, and pitfalls. Journal of

452 Clinical Microbiology. 2007;45(9):2761-4.

453 13. Patel JB. 16S rRNA gene sequencing for bacterial pathogen identification

454 in the clinical laboratory. Molecular diagnosis. 2001;6(4):313-21.

455 14. Idris AB, Hassan HG, Ali MAS, Eltaher SM, Idris LB, Altayb HN, et al.

456 Molecular Phylogenetic Analysis of 16S rRNA Sequences Identified Two

457 Lineages of Helicobacter pylori Strains Detected from Different Regions in Sudan

458 Suggestive of Differential Evolution. International Journal of Microbiology.

$459 \quad 2020 ; 2020: 8825718$.

460 15. Fan B, Blom J, Klenk H-P, Borriss R. Bacillus amyloliquefaciens, Bacillus

461 velezensis, and Bacillus siamensis Form an "Operational Group B.

462 amyloliquefaciens" within the B. subtilis Species Complex. Frontiers in

463 microbiology. 2017;8.

464 16. Rooney AP, Price NP, Ehrhardt C, Swezey JL, Bannan JD. Phylogeny and

465 molecular taxonomy of the Bacillus subtilis species complex and description of

466 Bacillus subtilis subsp. inaquosorum subsp. nov. International journal of

467 systematic and evolutionary microbiology. 2009;59(Pt 10):2429-36. 
468 17. Logan NA. Modern Methods for Identification. Applications and 469 Systematics of Bacillus and Relatives2002. p. 123-40.

470 18. Guinebretière $\mathrm{MH}$, Auger S, Galleron N, Contzen M, De Sarrau B, De

471 Buyser ML, et al. Bacillus cytotoxicus sp. nov. is a novel thermotolerant species

472 of the Bacillus cereus Group occasionally associated with food poisoning.

473 International journal of systematic and evolutionary microbiology. 2013;63(Pt

$474 \quad 1): 31-40$

475 19. Punina NV, Zotov VS, Parkhomenko AL, Parkhomenko TU, Topunov AF.

476 Genetic Diversity of Bacillus thuringiensis from Different Geo-Ecological Regions

477 of Ukraine by Analyzing the $16 \mathrm{~S}$ rRNA and gyrB Genes and by AP-PCR and 478 saAFLP. Acta naturae. 2013;5(1):90-100.

479 20. Tetreau G, Andreeva EA, Banneville AS, De Zitter E, Colletier JP. How 480 Does Bacillus thuringiensis Crystallize Such a Large Diversity of Toxins? Toxins. $481 \quad 2021 ; 13(7)$

482 21. Garbeva P, van Veen JA, van Elsas JD. Predominant Bacillus spp. in 483 agricultural soil under different management regimes detected via PCR-DGGE.

484 Microbial ecology. 2003;45(3):302-16.

485 22. Wilson MK, Abergel RJ, Raymond KN, Arceneaux JE, Byers BR. 486 Siderophores of Bacillus anthracis, Bacillus cereus, and Bacillus thuringiensis. 487 Biochemical and biophysical research communications. 2006;348(1):320-5. 
488 23. Raddadi N, Cherif A, Boudabous A, Daffonchio D. Screening of plant 489 growth promoting traits of Bacillus thuringiensis. Annals of Microbiology. $490 \quad 2008 ; 58: 47-52$.

491 24. Rabha M, Sharma S, Acharjee S, Sarmah BK. Isolation and characterization 492 of Bacillus thuringiensis strains native to Assam soil of North East India. 3 493 Biotech. 2017;7(5):303.

494 25. Sauka DH, Benintende GB. Diversity and distribution of lepidopteran495 specific toxin genes in Bacillus thuringiensis strains from Argentina. Revista 496 Argentina de microbiologia. 2017;49(3):273-81.

497 26. Nair K, Al-Thani R, Al-Thani D, Al-Yafei F, Ahmed T, Jaoua S. Diversity 498 of Bacillus thuringiensis Strains From Qatar as Shown by Crystal Morphology, 499 delta-Endotoxins and Cry Gene Content. Frontiers in microbiology. 2018;9:708.

500 27. Travers RS, Martin PA, Reichelderfer CF. Selective Process for Efficient 501 Isolation of Soil Bacillus spp. Applied and environmental microbiology. 502 1987;53(6):1263-6.

503 28. Baig DN, Mehnaz S. Determination and distribution of cry-type genes in 504 halophilc Bacillus thuringiensis isolates of Arabian Sea sedimentary rocks. 505 Microbiological research. 2010;165(5):376-83.

506 29. Centralblatt fu $\square \mathrm{r} \quad$ Bakteriologie, Parasitenkunde und 507 Infektionskrankheiten. 1. Abt. Originale. Jena :: G. Fischer; 1902. 
508 30. Yılmaz S, Ayvaz A, Azizoğlu U. Diversity and distribution of cry genes in 509 native Bacillus thuringiensis strains isolated from wild ecological areas of East-

510 Mediterranean region of Turkey. Tropical Ecology. 2017;58:605-10.

511 31. YILMAZ S. Molecular characterization of Bacillus thuringiensis strains

512 isolated from various habitats and their use against some harmful insects. Erciyes

513 University Research Information System: Erciyes University; 2010.

514 32. Cerón J, Ortíz A, Quintero R, Güereca L, Bravo A. Specific PCR primers

515 directed to identify cryI and cryIII genes within a Bacillus thuringiensis strain

516 collection. Applied and environmental microbiology. 1995;61(11):3826-31.

517 33. Bravo A, Sarabia S, Lopez L, Ontiveros H, Abarca C, Ortiz A, et al. 518 Characterization of cry genes in a Mexican Bacillus thuringiensis strain 519 collection. Applied and environmental microbiology. 1998;64(12):4965-72.

$520 \quad$ 34. FinchTV. 1.4.0 ed. USA: Geospiza, Inc.; Seattle, WA,; 2012.

521 35. Altschul SF, Madden TL, Schäffer AA, J Zhang ZZ, Miller W, Lipman DJ.

522 Gapped BLAST and PSI-BLAST. A new generation of protein database search 523 programmes. Nucleic Acids Res. 1997;25(17):3389-402.

524 36. Hall TA. BioEdit: a user-friendly biologicalsequence alignment editor 525 and analysis programfor Windows 95/98/NT. Nucl Acids Symp Ser $526 \quad 1999 ; 41: 95-8$

527 37. Kumar S, Stecher G, Tamura K. MEGA7: Molecular Evolutionary Genetics 528 Analysis Version 7.0 for Bigger Datasets. Molecular biology and evolution. $529 \quad 2016 ; 33(7): 1870-4$. 
530 38. Castresana J. Selection of Conserved Blocks from Multiple Alignments for

531 Their Use in Phylogenetic Analysis. Molecular Biology and Evolution.

$532 \quad 2000 ; 17(4): 540-52$.

533 39. Saitou N, Nei M. The neighbor-joining method: a new method for 534 reconstructing phylogenetic trees. Molecular biology and evolution. $535 \quad 1987 ; 4(4): 406-25$.

536 40. Goldman N. Maximum Likelihood Inference of Phylogenetic Trees, with 537 Special Reference to a Poisson Process Model of DNA Substitution and to 538 Parsimony Analyses. Systematic Biology. 1990;39(4):345-61.

539 41. Nei M, Kumar S. Molecular Evolution and Phylogenetics. USA: Oxford 540 University Press; 2000.

541 42. Felsenstein J. CONFIDENCE LIMITS ON PHYLOGENIES: AN 542 APPROACH USING THE BOOTSTRAP. Evolution; international journal of 543 organic evolution. 1985;39(4):783-91.

544 43. Patel JB. 16S rRNA gene sequencing for bacterial pathogen identification 545 in the clinical laboratory. Molecular diagnosis : a journal devoted to the 546 understanding of human disease through the clinical application of molecular 547 biology. 2001;6(4):313-21.

548 44. Stackebrandt E, Goebel BM. Taxonomic Note: a Place for DNA-DNA 549 Reassociation and 16s rRNA Sequence Analysis in the Present Species Definition 550 in Bacteriology1994. 
551 45. Castillo-Esparza JF, Hernández-González I, Ibarra JE. Search for Cry

552 proteins expressed by Bacillus spp. genomes, using hidden Markov model 553 profiles. 3 Biotech. 2019;9(1):13-.

554 46. Barloy F, Lecadet MM, Delécluse A. Cloning and sequencing of three new 555 putative toxin genes from Clostridium bifermentans CH18. Gene. 556 1998;211(2):293-9.

557 47. Zhang J, Hodgman TC, Krieger L, Schnetter W, Schairer HU. Cloning and 558 analysis of the first cry gene from Bacillus popilliae. Journal of bacteriology. 559 1997;179(13):4336-41.

560 48. Yokoyama T, Tanaka M, Hasegawa M. Novel cry gene from Paenibacillus 561 lentimorbus strain Semadara inhibits ingestion and promotes insecticidal activity 562 in Anomala cuprea larvae. Journal of invertebrate pathology. 2004;85(1):25-32.

563 49. Jones GW, Nielsen-Leroux C, Yang Y, Yuan Z, Dumas VF, Monnerat RG, 564 et al. A new Cry toxin with a unique two-component dependency from Bacillus 565 sphaericus. FASEB journal : official publication of the Federation of American 566 Societies for Experimental Biology. 2007;21(14):4112-20.

567 50. Ben-Dov E, Zaritsky A, Dahan E, Barak Z, Sinai R, Manasherob R, et al. 568 Extended screening by PCR for seven cry-group genes from field-collected 569 strains of Bacillus thuringiensis. Applied and environmental microbiology. $570 \quad$ 1997;63(12):4883-90.

571 51. Feitelson JS, Payne J, Kim L. Bacillus thuringiensis: Insects and Beyond. 572 Bio/Technology. 1992;10(3):271-5. 
573 52. Shishir A, Roy A, Islam N, Rahman A, Khan SN, Hoq MM. Abundance

574 and diversity of Bacillus thuringiensis in Bangladesh and their cry genes profile.

575 Frontiers in Environmental Science. 2014;2(20).

576 53. Rabha M, Acharjee S, Sarmah BK. Multilocus sequence typing for

577 phylogenetic view and vip gene diversity of Bacillus thuringiensis strains of the

578 Assam soil of North East India. World journal of microbiology \& biotechnology.

$579 \quad 2018 ; 34(7): 103$.

580 54. Gassmann AJ, Shrestha RB, Kropf AL, St Clair CR, Brenizer BD. Field-

581 evolved resistance by western corn rootworm to Cry34/35Ab1 and other Bacillus

582 thuringiensis traits in transgenic maize. Pest management science. 2020;76(1):268-

58376.

584 55. Liu Y, Du J, Lai Q, Zeng R, Ye D, Xu J, et al. Proposal of nine novel species

585 of the Bacillus cereus group. International journal of systematic and evolutionary

586 microbiology. 2017;67(8):2499-508.

587 56. Zothansanga R, Senthilkumar N, Gurusubramanian G. Diversity and 588 Toxicity of Bacillus thuringiensis from Shifting Cultivation (Jhum) Habitat.

589 Biocontrol science. 2016;21(2):99-111.

590 57. Helgason E, Caugant DA, Lecadet MM, Chen Y, Mahillon J, Lovgren A, et

591 al. Genetic diversity of Bacillus cereus/B. thuringiensis isolates from natural 592 sources. Current microbiology. 1998;37(2):80-7.

593 58. Gdoura-Ben Amor M, Siala M, Zayani M, Grosset N, Smaoui S, Messadi594 Akrout F, et al. Isolation, Identification, Prevalence, and Genetic Diversity of 
595 Bacillus cereus Group Bacteria From Different Foodstuffs in Tunisia. Frontiers in 596 microbiology. 2018;9(447).

597 59. Gordon REHWCPCH-NSNR. The genus Bacillus. Washington, D.C.: 598 Agricultural Research Service, U.S. Dept. of Agriculture : For sale by Supt. of 599 Docs., U.S. $\quad$ G.P.O.; $1973 . \quad$ Available from: 600 http://books.google.com/books?id=1XMpXssWFD0C.

601 60. Kwok P-Y. Single Nucleotide Polymorphisms (SNPs): Identification and 602 Scoring. eLS.

603 61. Dimauro C, Cellesi M, Steri R, Gaspa G, Sorbolini S, Stella A, et al. Use of 604 the canonical discriminant analysis to select SNP markers for bovine breed 605 assignment and traceability purposes. Animal Genetics. 2013;44(4):377-82.

606 62. Griffing SM, MacCannell DR, Schmidtke AJ, Freeman MM, Hyytiä-Trees 607 E, Gerner-Smidt P, et al. Canonical Single Nucleotide Polymorphisms (SNPs) for 608 High-Resolution Subtyping of Shiga-Toxin Producing Escherichia coli (STEC) 609 O157:H7. PLoS One. 2015;10(7):e0131967.

610 63. Fernandez-No IC, Bohme K, Caamano-Antelo S, Barros-Velazquez J, Calo611 Mata P. Identification of single nucleotide polymorphisms (SNPs) in the 16S 612 rRNA gene of foodborne Bacillus spp. Food microbiology. 2015;46:239-45.

613 64. Pillidge CJ, Sheehy LM, Shihata A, Pu Z-Y, Dobos M, Powell IB. 614 Intragenomic 16S rRNA gene heterogeneity in Lactococcus lactis subsp. cremoris. 615 International Dairy Journal. 2009;19(4):222-7. 
616 65. Hakovirta JR, Prezioso S, Hodge D, Pillai SP, Weigel LM. Identification

617 and Analysis of Informative Single Nucleotide Polymorphisms in 16S rRNA

618 Gene Sequences of the Bacillus cereus Group. Journal of clinical microbiology.

$6192016 ; 54(11): 2749-56$.

620 66. Sacchi CT, Whitney AM, Mayer LW, Morey R, Steigerwalt A, Boras A, et

621 al. Sequencing of $16 S$ rRNA gene: a rapid tool for identification of Bacillus

622 anthracis. Emerging infectious diseases. 2002;8(10):1117-23.

623 67. Keim P, Van Ert MN, Pearson T, Vogler AJ, Huynh LY, Wagner DM.

624 Anthrax molecular epidemiology and forensics: using the appropriate marker for

625 different evolutionary scales. Infection, genetics and evolution : journal of

626 molecular epidemiology and evolutionary genetics in infectious diseases.

$627 \quad 2004 ; 4(3): 205-13$.

628 68. Moorhead SM, Dykes GA, Cursons RT. An SNP-based PCR assay to

629 differentiate between Listeria monocytogenes lineages derived from

630 phylogenetic analysis of the sigB gene. Journal of microbiological methods.

$631 \quad 2003 ; 55(2): 425-32$.

632 69. Van Ert MN, Easterday WR, Simonson TS, U'Ren JM, Pearson T, Kenefic

633 LJ, et al. Strain-specific single-nucleotide polymorphism assays for the Bacillus

634 anthracis Ames strain. Journal of clinical microbiology. 2007;45(1):47-53. 
bioRxiv preprint doi: https://doi.org/10.1101/2021.12.24.474129; this version posted December 24, 2021. The copyright holder for this preprint (which was not certified by peer review) is the author/funder, who has granted bioRxiv a license to display the preprint in perpetuity. It is made available under aCC-BY 4.0 International license.

b)

\begin{tabular}{|c|}
\hline 1. NZ_CM000747-B. thuringiensis Bt407 \\
\hline 2. CP010005- B. thuringiensis serovar kurstaki strain HD 1 \\
\hline 3. NR_043403-B. thuringiensis strain IAM 12077 \\
\hline 4. NR_114581-B. thuringiensis strain ATCC 10792 \\
\hline 5. NR_115714-B. cereus strain CCM 2010 \\
\hline 6. NR_115526-B. cereus strain IAM 12605 \\
\hline 7. NR_114582-B. cereus strain ATCC 14579 \\
\hline 8. SY49.1 \\
\hline 9. PSY16.2A \\
\hline 10. PSY13.3A \\
\hline 11. PSY6.1A \\
\hline 12. PSY6.2A \\
\hline 13. PSY18.2A \\
\hline 14. PSY28.1A \\
\hline 15. SY10.1A \\
\hline 16. SY29.1A \\
\hline 17. SY29.2 \\
\hline 18. SY25.1A \\
\hline
\end{tabular}

c)

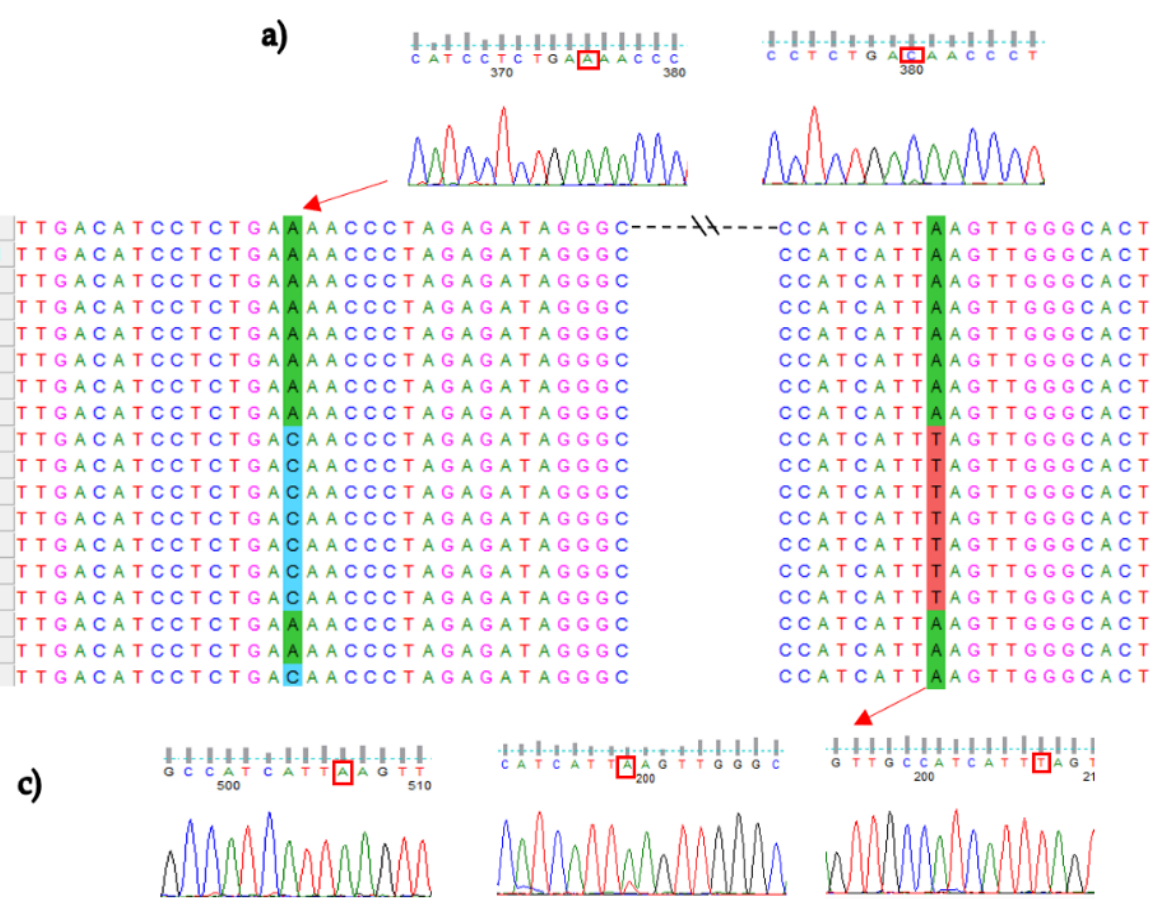

Figure 1. 1a) and 1b) Sequencing results of chromatograms using Finch TV software show nucleotide changes in the $16 S$ rRNA gene of B. cereus / B. thuringiesis strains illustrated by squares. 1c) Multiple sequences alignment of the native Bacillus strains that belong to B. cereus group using ClustalW. 
a)

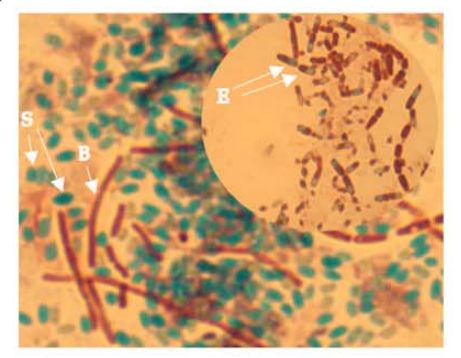

b)

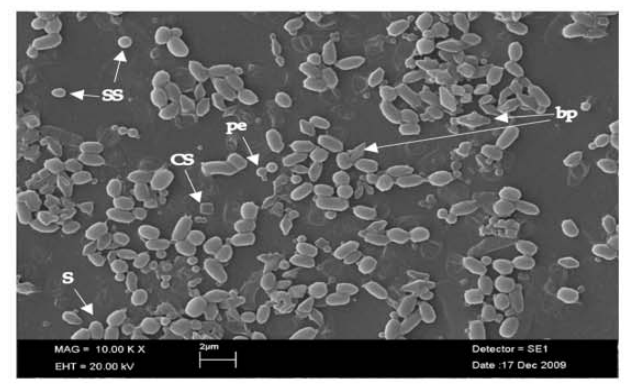

c)

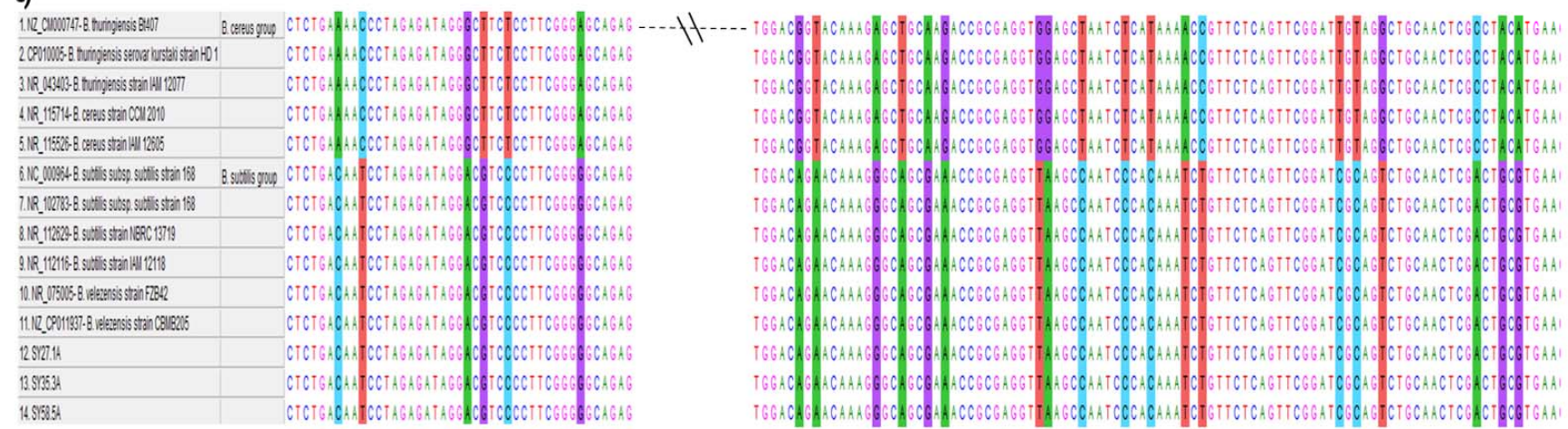

Figure 2. 2a) Microscopic view of native Bacillus strains after spore staining (1000x). B, Bacillus bacteria; S, spores; E, endospores. 2b) Scanning electron microscopy (SEM) image of the different types of crystal morphologies and the spores (S) produced by native Bacillus strain SY27.1A isolated from soil sample. SS, smooth spherical crystal; pe, spherical crystal with pointy edges; bp, bipyramidal crystal; cs, cuboidal crystal. 2c) Multiple Sequence Alignment (MSA) of $16 S$ rRNA sequences of the three native strains (SY27.1A, SY35.3A, SY58.5A) shows high similarity with $B$. subtilis group rather than species of $B$. cereus group. 
bioRxiv preprint doi: https://doi.org/10.1101/2021.12.24.474129; this version posted December 24, 2021. The copyright holder for this preprint (which was not certified by peer review) is the author/funder, who has granted bioRxiv a license to display the preprint in perpetuity. It is made available under aCC-BY 4.0 International license.

a)

\begin{tabular}{|c|c|c|c|c|}
\hline INC,00004- e wath & 8 astals youp & $A, F C C$ & $\operatorname{coc} c+t c g e c$ & $\sigma C A G$ \\
\hline 2MQ 10272 - sustes & & CCTCTGACAATCCTAGAGATAGG & cectregege & \\
\hline 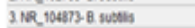 & & CCTCTGACAATCCTAGAGATAGG & сссCTTGGGQG & CCAGAG \\
\hline AMQ.12116-8 sutals & & CCTCTGACAATCCTAGAGATAGCA & ССCCTTCOQOOG & CCAGAO \\
\hline S.MQ 112628 . B sutath & & CCTCTOACAATCCTAGAOATAGO & CCCCTTCOOOC & $D C A O A O$ \\
\hline 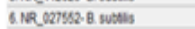 & & CCTCTGACAATCCTAGAOATAGO & TCCOCTTCOOOG & COAOAO \\
\hline 7.Me. 12606- B waths & & CCTCTGACAATCCTAGAGATAGO & CCCCTTCGOGG & $D C A G A G$ \\
\hline Ane 1120se matis & & CCTCTGACAATCCTAGAGATAGGAC & TCCCCTTCGGG & $C A A G A G$ \\
\hline 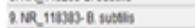 & & CCTCTGACAATCCTAGAGATAGG & CCCCTICGGGG & $C C A G A G$ \\
\hline 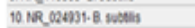 & & CCTCTGACAATCCTAGAGATAGG & TCCCCTTCGGG & CCAGAG \\
\hline 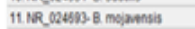 & & CCTCTGACAATCCTAGAGATAOC & СсCотTCGQGQ & DCAGAG \\
\hline 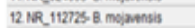 & & CCTCTOACAATCCTAOAOATAGO & TCCCCTTCOOOG & $D C A G A O$ \\
\hline 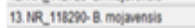 & & CCTCTOACAATCCTAOAGATAOO & CCCCTTCOOOG & $D C A Q A O$ \\
\hline 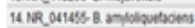 & & CCTCTGACAATCCTAGAOATAGO & TCCCCTTCOOQO & CCAGAG \\
\hline 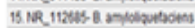 & & CCTCTGACAATCCTAGAGATAGG & CCCCTTCGGGG & CCAGAG \\
\hline 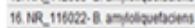 & & CCTCTGACAATCCTAGAGATAGG & TCCCCTTCGGG & $C C A G A G$ \\
\hline 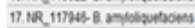 & & CCTCTGACAATCCTAGAGATAGG & сссотTCGgQG & CCAGAG \\
\hline 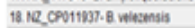 & & CCTCTGACAATCCTAGAGATAGO & TCсCоTtcgoge & $\operatorname{CAAGAO}$ \\
\hline 19.1R_.075005 \& vilesemis & & CCTCTOACAATCCTAGAOATAGO & CCCCTTCOOQO & $D C A Q A G$ \\
\hline sossu & & CCTCTOACAATCCTAOAOATAGO & TCCCCTTCOOOQ & CCAGAO \\
\hline 21 ร272.4 & & CCTCTGACAATCCTAGAOATAOCA & $T C C C C T T C O O O C$ & CCAOAG \\
\hline ase & & CCTCTGACAATCCTAGAGATAGG & CCCCTTCGGGG & CCAGAG \\
\hline 21 250 & & CCTCTGACAAFCCTAGAGATAGGA & CCCCTTCGOGG & CGAGAG \\
\hline dit & & CCTCTGACAATCCTAGAGATAGG & CсcCTTCGgGG & CCAGAG \\
\hline 25.9205 & & CCTCTGACAATCCTAGAGATAGOA & сссетTCGgGG & $C A G A G$ \\
\hline B punidus & Bpount & CCCTCTOACAACCCTAGAGATAGO & TсCCTTCOQOQ & NCAGAG \\
\hline 27.MR.112637. \& pundis & & CCTCTOACAACCCTAGAOATAGO & TCCOTTCOOOO & CAAGAO \\
\hline 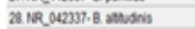 & & CCTCTOACAACCCTAGAGATAGO & CCCTTCOOOG & $A A C A Q A O$ \\
\hline 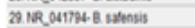 & & CCTCTGACAACCCTAGAGATAGO & TCCOTTCOOGG & $A C A G A G$ \\
\hline 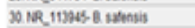 & & CCTCTGACAACCCTAGAGATAGG & TCCOTTCGGGG & $A A C A G A G$ \\
\hline 31 รकाष & & CCTCTGACAACCCTAGAGATAGG & TCCOTTGGGG & CCAGAG \\
\hline $12 \sin$ & & CCTCTGACAACCCTAGAGATAGG & CCCTTCG & $\operatorname{CAGAG}$ \\
\hline 35 & & CCTCTGACAACCCTAGAGATAGO & TCCOTtCOS & 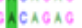 \\
\hline 34 5183 & & CCTCTOACAACCCTAOAOATAOC & CCCOTTCOOOG & \\
\hline
\end{tabular}

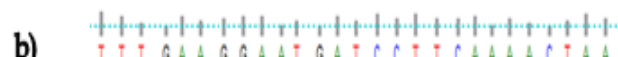

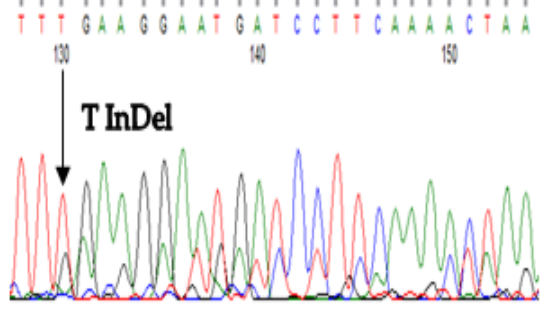

SY82

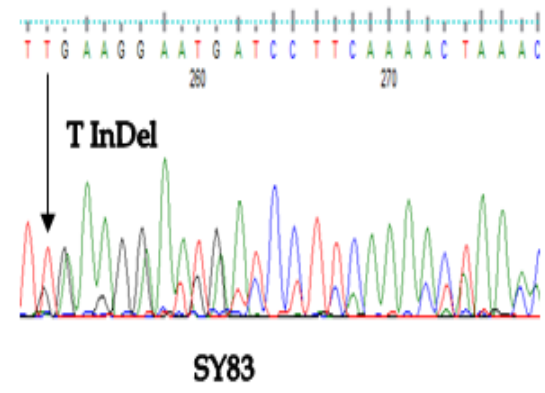

Figure 3. 3a) Multiple sequences alignment (MSA) of B. subtilis group shows 11 canonical SNPs (canSNPs) in strains that belong to B. pumilus groups when compared with B. subtilis reference sequences. 3b) Sequencing results of chromatograms illustrate the loss of synchronicity in SY82 and SY83 strains due to a nucleotide deletion or insertion within one or more of the 16S rRNA genes among the multiple $r R N A$ operons in the genome. 


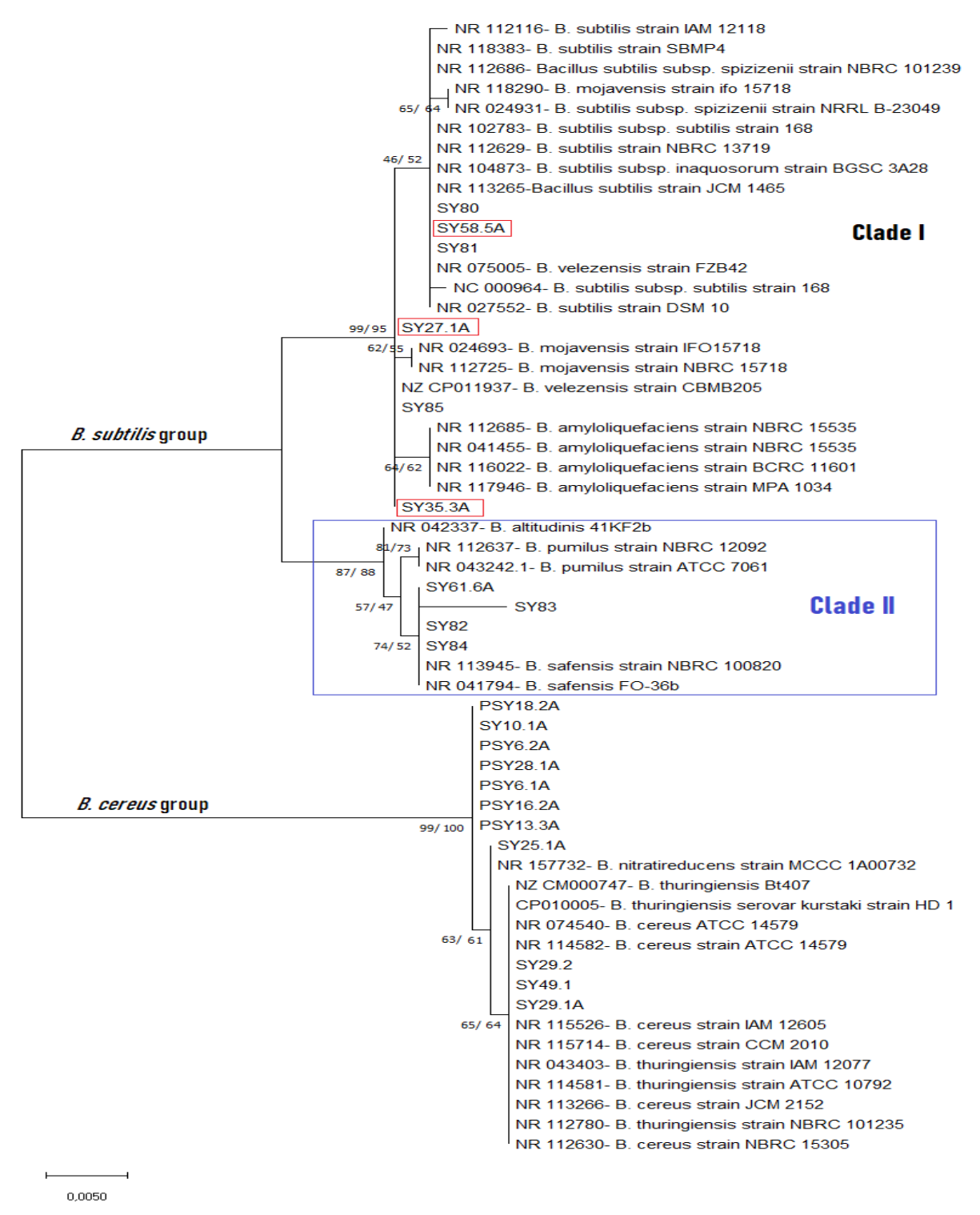

Figure 4. Maximum-Likelihood Phylogenetic tree of native Bacillus strains isolated from Turkey. The percentage of replicate trees (1000 replicates) are shown next to the branches from both NJ (before the slash '/') and ML (after the slash '/') analyses. The ML tree is only shown here, because the ML tree was very similar to the $\mathrm{NJ}$ tree. The evolutionary distance was computed using $(\mathrm{K} 2+\mathrm{G})$ model and evolutionary analyses were conducted using MEGA7. 
bioRxiv preprint doi: https://doi.org/10.1101/2021.12.24.474129; this version posted December 24,2021 . The copyright holder for this preprint (which was not certified by peer review) is the author/funder, who has granted bioRxiv a license to display the preprint in perpetuity. It is made available under aCC-BY 4.0 International license. 


\section{Highlights}

- Isolation and characterization of native Bacillus strains from agricultural soil should receive a good attention because of their wide potential biological products with immense applications.

- Identification of three native strains (SY27.1A, SY35.3A, and SY58.5A), which produce Cry proteins, shared high similarity with B. subtilis group (over 99\%) and less than $95 \%$ similarity with known $B$. thuringiensis and other species of $B$. cereus group.

- Eleven canonical SNPs (canSNPs) were detected in strains that belong to B. pumilus group when compared with B. subtilis reference sequences.

- The SNP at nucleotide position 1146 is not necessarily reliable for identifying $B$. anthracis, while $\mathrm{G}$ at position 1139, which is another SNP proposed to be unique to $B$. anthracis, appears to be more reliable for identifying B. anthracis.

- Phylogenetic analysis of $16 S$ rRNA sequences was found valuable for differentiation between Bacillus species isolated from soil samples. 